\title{
Nationwide continuous monitoring of end-of-life care via representative networks of general practitioners in Europe
}

Lieve Van den Block ${ }^{*}$, Bregje Onwuteaka-Philipsen², Koen Meeussen ${ }^{1}$, Gé Donker $^{3}$, Francesco Giusti ${ }^{4}$, Guido Miccinesi ${ }^{4}$, Viviane Van Casteren ${ }^{5}$, Tomas Vega Alonso ${ }^{6}$, Oscar Zurriaga ${ }^{7,8}$ and Luc Deliens ${ }^{1,2}$

\begin{abstract}
Background: Although end-of-life care has become an issue of great clinical and public health concern in Europe and beyond, we lack population-based nationwide data that monitor and compare the circumstances of dying and care received in the final months of life in different countries. The European Sentinel GP Networks Monitoring End of Life Care (EURO SENTIMELC) study was designed to describe and compare the last months of life of patients dying in different European countries. We aim to describe how representative GP networks in the EURO SENTIMELC study operate to monitor end of life care in a country, to describe used methodology, research procedures, representativity and characteristics of the population reached using this methodology.
\end{abstract}

Methods: Nationwide representative Networks of General Practitioners (GPs) - ie epidemiological surveillance systems representative of all GPs in a country or large region of a country - in Belgium, the Netherlands, Italy and Spain continuously registered every deceased patient (>18 year) in their practice, using weekly standardized registration forms, during two consecutive years (2009-2010).

All GPs were asked to identify patients who had died "non-suddenly". The last three months of these patients' lives was surveyed retrospectively. Several quality control measures were used to ensure data of high scientific quality.

Results: A total of 6858 deaths were registered of which two thirds died non-suddenly (from $62 \%$ in the Netherlands to $69 \%$ in Spain), representative for the GP populations in the participating countries. Of all nonsudden deaths, between $32 \%$ and $44 \%$ of deaths were aged 85 or older; between $46 \%$ and $54 \%$ were female, and between $23 \%$ and $49 \%$ died at home. Cancer was cause of death in 37\% to 53\% of non-sudden death cases in the four participating countries.

Conclusion: Via the EURO SENTI-MELC methodology, we can build a descriptive epidemiological database on end-of-life care provision in several EU countries, measuring across setting and diseases. The data can serve as baseline measurement to compare and monitor end-of-life care over time. The use of representative GP networks for end-of-life care monitoring has huge potential in Europe where several of these networks are operational.

Keywords: Palliative care, Monitoring, End of life

\footnotetext{
* Correspondence: Ivdblock@vub.ac.be

'End-of-Life Care Research Group, Vrije Universiteit Brussel and Ghent

University, Laarbeeklaan 103, Brussels 1090, Belgium

Full list of author information is available at the end of the article
} 


\section{Background}

How people die and the care delivered in the final phase of life has become an issue of great clinical and public health importance [1,2]. Nevertheless, population-based and nationwide research monitoring the circumstances surrounding death and the quality of the end-of-life care provided in the final months of life is limited [3-5]. Existing empirical research is often restricted to specific populations of patients such as cancer patients or elderly people, to specific settings such as hospitals, hospices, or nursing homes, or is focused on a specific aspect of end-of-life care provision, thus providing only a limited view on how people are dying in a society [6-13]. Also, research exploring large-scale databases such as disease registries or healthcare billing data, or once-only population-based surveys studying quality end-of-life care is primarily restricted to the UK, Canada and US [14-17].

Furthermore, comparison of practices in different countries is often not feasible due to the use of different methodologies in different populations. One exception concerns the international analyses of mortality statistics based on official death certification, showing how many people die, at what age, from what causes, and where $[6,13]$, but not including important other parameters of the quality of end-of-life care such as the use of palliative care, hospitalisations and transitions between settings, or communication at the end of life. Gathering such epidemiological data is pivotal to developing an effective public health policy on end-of-life care on a national and European level [5].

Because the general practitioner (GP) has a pivotal role in end-of-life care delivery in most countries in Europe operating across care settings and patient populations and because several countries within Europe have an operating Sentinel Network of General Practitioners representative of all GPs in the country or region - the EURO SENTIMELC methodology offers unique possibilities to describe and compare end-of-life care in Europe on a continuous basis [18-21]. SENTIMELC refers to "Sentinel Network Monitoring End-of-Life Care", an ongoing study which first started in Belgium in 2004 and in the Netherlands in 2005 and since 2009-2010 also involving Italy and Spain, focusing on describing and comparing end-of-life care in the last three months of life in different European countries - Belgium, the Netherlands, Italy and Spain in 2009-2010 - via the use of a representative network of GPs.

\section{Aims of the study}

The objective of this report is to describe how representative GP networks in the EURO SENTIMELC study operate to monitor end-of-life care in a country, to describe used methodology and research procedures, and to present representativity and characteristics of the population reached using this methodology in 2009 and 2010. We hope that our experience in these 4 EU countries will be useful to others, in particular to countries with analogue surveillance networks of general practitioners who wish to integrate end-of-life care research into their registrations.

\section{Methods}

Because of the problems with prognosticating who is dying in prospective end-of-life care research [22,23], we designed a continuous mortality follow-back study with data collection shortly after the patient had died, using a standardized registration form to be filled in weekly by the GP. The EURO SENTIMELC study was performed in 2009 and 2010 with data gathering in Belgium, the Netherlands, Italy and Spain (the latter limited to 2010 only). This European study is an expansion of the SENTIMELC study which first started in 2004 in Belgium and in the Netherlands in 2005 with continuing registrations since then. Several results for these two individual countries have been reported in previous publications [19,21,24-28]. In Table 1 an overview of all partners of EURO SENTIMELC is provided.

\section{Observational unit}

In this study, GPs are the observational units. Within Europe, general practice is highly accessible. GPs generally can provide a good public health perspective on end-of-life care and dying in the country. In some countries (e.g. the Netherlands, Spain), they are gatekeepers for healthcare delivery i.e. primary care providers who coordinate patient care and provide referrals to specialist services. In other countries (e.g. Belgium, Italy) they are not gatekeepers but do have a central coordinating role in the healthcare system with almost all of the population having a regular GP who they consult regularly. Hence, we use GPs in this study to generate a population-based sample of deaths. One important exception concerns the specialist nursing homes in the Netherlands since nursing home residents are treated by their own elderly care physicians and are thus outside of the view of the GP. Of all deaths in the Netherlands, $22 \%$ occurred in a nursing home in 2005 and average length of stay is more than one year.

In Belgium, the Netherlands and Spain existing Sentinel Networks of General Practitioners (GPs) are used as the observational unit in this study. A Sentinel Network of GPs is "a network of practices or community based physicians who monitor one, several or an exhaustive list of health problems on a regular or continuing basis". The information from these practices is used to monitor the health of the entire population $[18,29,30]$. Recorded data must concern an important health problem not 
Table 1 EURO SENTIMELC consortium 2009-2010

\begin{tabular}{|c|c|c|c|c|}
\hline & Belgium - coordinator & The Netherlands & Italy & Spain \\
\hline Research institution & $\begin{array}{l}\text { VUB-UGent End-of-Life } \\
\text { Care Research Group, Vrije } \\
\text { Universiteit Brussel }\end{array}$ & $\begin{array}{l}\text { VU University Medical Center, } \\
\text { EMGO Institute for Health and } \\
\text { Care Research, Department of } \\
\text { Public and Occupational Health }\end{array}$ & $\begin{array}{l}\text { ISPO, Cancer Prevention } \\
\text { and Research Institute }\end{array}$ & $\begin{array}{l}\text { Directorate General of } \\
\text { Public Health, Consejería } \\
\text { de Sanidad, Valladolid }\end{array}$ \\
\hline GP network & $\begin{array}{l}\text { "Huisartsenpeilpraktijken", } \\
\text { the Belgian Sentinel Network } \\
\text { of General Practitioners, } \\
\text { coordinated by the Institute } \\
\text { of Public Health, OD Public } \\
\text { Health and Surveillance }\end{array}$ & $\begin{array}{l}\text { "Continu Morbiditeitsregistratie } \\
\text { Peilstations", the Dutch Sentinel } \\
\text { Network of General Practitioners, } \\
\text { coordinated by the NIVEL Institute }\end{array}$ & $\begin{array}{l}\text { Network from the Italian } \\
\text { Society of General } \\
\text { Practitioners }\end{array}$ & $\begin{array}{l}\text { Health Sentinel Network } \\
\text { of Castilla y León and the } \\
\text { Health Sentinel Network } \\
\text { of Comunitat Valenciana }\end{array}$ \\
\hline
\end{tabular}

subject to surveillance of another system, unless the Sentinel Network provides complementary information to this end.

Given the existing Italian sentinel network mainly focuses on flu surveillance, the Italian partner has built its own GP network representative for the country and only performing registration regarding the end of life. To avoid selection of GPs more trained than the average GP in palliative care, Italian physicians were enrolled by the 9 coordinators of the participating health districts only specifying the procedure and not the content of the research. Participating physicians were sampled stratifying by age and sex, to assure representativeness of the GPs operating in the involved districts. Also, an extensive pilot phase was performed.

In Belgium, the GPs have been selected to cover the whole country and form a representative sample of GPs in the country. Each year, the responsible Institute for Public Health monitors the stability of the network (there is an annual turnover of $10 \%$ on average), verifies its representativity comparing age, gender and geographical distribution of the sentinel GPs with characteristics of the total GP population in Belgium, and calculates the percentages of the population coverage per district. Reports are published in in Dutch and French [31].

In the Netherlands (with an annual turnover of less than 5\%), GPs are also selected to cover the whole country and each year the responsible institute verifies the representativity of the GP sample in terms of geographical distribution, urbanization, age and gender compared with the total GP population. Additionally, the sample of the population reached by the sentinel GPs is yearly compared in terms of age and gender with the whole patient population, to verify the representativity of the network - which is not possible for Belgium due to the lack of patient lists. These data are included in the yearly reports of the Dutch sentinel practices [32].

In Spain (with an annual turnover of less than 5\%), the same procedures as in the Netherlands are performed within the two large regions in the Centre and East of Spain (Castilla y León and Valencia) to ensure representativity at GP and patient level. Spanish methodologies for setting up the sentinel networks have previously been published [30]. Sentinel GPs are randomly selected into clusters of the population to have the best representativity of the covered population. Age and sex distribution, as well as the socioeconomic status of the population is periodically compared to the general population of the regions [33-35].

In Italy, the nine health districts in the newly set up Sentinel Network of GPs are spread all over the country with three of them in large metropolitan cities (Genova, Palermo, Napoli). GPs were found representative in terms of age and gender in all 9 health districts participating (distributed in all of the four Italian statistical macro-areas). The distribution by age, sex and calendar period (month) of deaths registered by the Network was successfully compared with the last available national mortality statistics (2008).

All networks have in common that the participation of the GPs is voluntarily, and feedback is regularly distributed to the participants, concerned authorities, the medical press, scientific associations and interested individuals. The turnover of the GPs, from year to year, is low, which contributes to the collection of data of high scientific quality. Also, only regularly participating GPs (i.e. who register at least 26 weeks per year) are included for data analyses.

Further details on the participating GP networks can be found in Table 2 .

\section{Study population}

The unit of measurement in the EURO SENTI-MELC study was the death case. Primary inclusion criteria were:

- every patient, part of the practice of the GP, who had died (certified deaths and deaths of which they were informed afterwards)

- aged 18 year or older

In order to focus this study on care delivered at the end of life or on dying patients (i.e. patients who were theoretically able to receive care in the terminal phase of life) we additionally excluded all deaths that had 
Table 2 Characteristics of the participating GP networks in the EURO SENTIMELC study 2009-2010

\begin{tabular}{|c|c|c|c|c|}
\hline & Belgium & The Netherlands & Italy & Spain \\
\hline $\begin{array}{l}\text { Coordinating } \\
\text { institution }\end{array}$ & Institute of Public Health & NIVEL Institute & $\begin{array}{l}\text { Italian Society of } \\
\text { General Practitioners }\end{array}$ & $\begin{array}{l}\text { Directorate General } \\
\text { of Public Health }\end{array}$ \\
\hline Founded in & 1979 & 1970 & 2009 & 1988 \\
\hline $\begin{array}{l}\text { Years of participation } \\
\text { in EURO SENTIMELC } \\
\text { study }\end{array}$ & Since 2004 and ongoing & Since 2005 and ongoing & 2009 and 2010 & 2010 \\
\hline Participating regions & Country wide & Country wide & Country wide & $\begin{array}{l}\text { Castilla y León (north) } \\
\text { and Valencia (south) }\end{array}$ \\
\hline $\begin{array}{l}\text { Number of GP } \\
\text { practices and general } \\
\text { patient population } \\
\text { coverage }\end{array}$ & $\begin{array}{l}+/-200 \mathrm{GPs}(+/-170 \mathrm{GP} \\
\text { practices) Covering } 1.75 \% \\
\text { of the total Belgian population }\end{array}$ & $\begin{array}{l}+/-59 \text { GPs (in } 42 \text { GP } \\
\text { practices) Covering 0,8\% } \\
\text { of the total Dutch population }\end{array}$ & $\begin{array}{l}149 \text { GPs participating in } \\
2009 \text {; and } 94 \text { GPs in } 2010 \\
\text { Covering +/- 3-4\% of } \\
\text { population per health district }\end{array}$ & $\begin{array}{l}+/-114 \text { GPs covering } 3,5 \% \\
\text { of the total }+18 y \text { population } \\
\text { in Castilla y León; and } 59 \text { GPs } \\
\text { covering 2,2\% in Valencia }\end{array}$ \\
\hline $\begin{array}{l}\text { Representativity of the } \\
\text { GP network in the } \\
\text { country }\end{array}$ & $\begin{array}{l}\text { Representative of all GPs in } \\
\text { Belgium in terms of age, } \\
\text { gender and geographical } \\
\text { distribution, and also of the } \\
\text { GPs in the Northern } \\
\text { (Dutch-speaking) and Southern } \\
\text { (French-speaking) regions }\end{array}$ & $\begin{array}{l}\text { Representative of all Dutch } \\
\text { GPs in terms of geographical } \\
\text { distribution and urbanization, } \\
\text { age and gender }\end{array}$ & $\begin{array}{l}\text { Representative of all GPs } \\
\text { in terms of age and gender } \\
\text { in all } 9 \text { health districts } \\
\text { participating (distributed in } \\
\text { all of the four Italian } \\
\text { statistical macro-areas) }\end{array}$ & $\begin{array}{l}\text { Representative for the } 2 \\
\text { participating Sentinel GP } \\
\text { Networks: Castilla y León } \\
\text { and Valencia, in terms of } \\
\text { age, gender, urbanization } \\
\text { and other geographical } \\
\text { variables }\end{array}$ \\
\hline
\end{tabular}

occurred "suddenly and totally unexpectedly" for some research questions $[20,36,37]$.

\section{Retrospective data collection procedure}

For the purpose of this study, the GPs registered deaths via a continuous and weekly standardized registration form, during 2 consecutive years (2009-2010) from January 1st until December $31^{\text {st }}$, except for Spain that joined the study in 2010. In Italy, GPs registered via a web based electronic questionnaire while in all other countries GPs used paper and pencil (expect for Valencia that uses electronic registering). To shorten the time between death and registration - hence preventing recall bias as much as possible - the physicians were instructed to register all deaths, immediately after being informed about the patient's death. GPs use patient records and information coming from hospital physicians as much as possible when filling in the forms. GPs are sent accompanying instructions at the beginning of each year, clearly stating the inclusion criteria of the study and clarifying the manner in which some questions need to be filled in. The specific operating procedures that are used by an existing Sentinel Network are also followed for the end-of-life care registration. Table 3 provides details on the data collection procedures in each country.

\section{Definition of concepts}

In this study, we mainly focus on the final three months of life of patients and investigate several important components of quality of end-of-life care: places of care and death, transitions between care settings; communication; palliative care provision; symptoms in the last week of life; and costs/burden of end-of-life care. These domains have been identified in international literature as important components of quality of end-of-life care $[15,16,38-40]$, and are particularly relevant from the GP perspective not being under surveillance via other instruments.

Transitions between end-of-life care settings were defined as moves or changes in location of care during the last three months of life. Home (or with relatives, in service flats), care home (including homes for elderly people in all four countries and nursing homes in Belgium, Italy and Spain excluding the specialist Dutch nursing homes), hospital and inpatient palliative care unit, were differentiated.

Concerning communication we differentiated between:

- topics addressed during conversations between GP and the patient

- elements of advance care planning:

- preferences for place of death

- wishes about a medical treatment $\mathrm{s} /$ he would or would not want in the final phase of life

- wish for a proxy decision-maker

Palliative care was studied in terms of palliative care delivered by the GP and specialist multidisciplinary palliative care [1]. As there are differences in the types of multidisciplinary palliative care services offered in each country, each service was classified into one of three categories in order to facilitate comparison, as shown in Table 4.

\section{Measurement instrument}

A majority of the items are pooled from existing registration forms used in the SENTIMELC study in Belgium and the Netherlands. These were developed on the basis 
Table 3 Data collection procedures of the participating GP networks in the EURO SENTIMELC study 2009-2010

\begin{tabular}{llll}
\hline Data collection procedures & Belgium & The Netherlands & Italy \\
\hline $\begin{array}{l}\text { Frequency and mode } \\
\text { of reporting }\end{array}$ & Weekly reporting Paper and pencil & Weekly reporting Paper and pencil & $\begin{array}{l}\text { Weekly reporting online web based } \\
\text { registration (Emailing with memo } \\
\text { sent weekly) }\end{array}$
\end{tabular}

of reporting

Extra quality control measures -selection of regular participating GPs (registered 26 weeks or more of one year)

-data entry by the Institute of Public to prevent key punching errors, double data entry by VUB

-automatic follow-up forms to prevent missing data for key variables; telephone contact with GP also possible

-GPs received summaries of all reported deaths after each year of registration (2005-2006 to verify for possible

(2005-2006 to verify for possible
non-response (e.g. GPs who forgot to report one of their deaths)

Anonymity procedures

-anonimization of patient data upon data entry

-anonimization of physician data when closing database

Training for GPs

\section{Spain} Health using dbase-based programme

-selection of regular participating Gs (registered 26 weeks or more of one year)

-it concerned a new network only involving GPs that agreed to participate for a whole year

-data entry by researchers, $5 \%$ with double data entry

-reminders send by NIVEL after checking for missing data on key variables; if necessary telephone contact with GP

-GPs have patient lists

-web based application needing no data entry and ensuring all necessary items are filled in

-weekly reminders (an e-mail with a memo was sent weekly to assure the ready reporting of deceased cases)

-GPs have patient lists -anonimization of patient data upon data entry

-anonimization of physician data when closing database

-registration instructions each year -anonimization of patient data when registering

-anonimization of physician data when closing database

-registration instructions via coordinating

GPs per health district at the

beginning of the year
No weekly reporting: deaths are

reported the week of the event however GPs are used to send in a weekly report form on other health problems

Paper and pencil for Castilly y Léon electronic registry for Valencia

-selection of regular participating GPs (registered 26 weeks or more of one year)

-data entry by province coordinators, using dbase-based programme to prevent key punching errors; no double data entry

-reminders to GPs when missing data or inconsistencies

-anonimization of patient data upon data entry in Castilla and after data recording in Valencia

-anonimization of physician data when closing database

-registration instructions each year basic parameters 
Table 4 Specialist multidisciplinary palliative care services in the four participating countries of the EURO SENTIMELC study

\begin{tabular}{|c|c|c|c|c|}
\hline & Belgium & Netherlands & Italy & Spain \\
\hline Hospice/palliative care unit & Palliative care unit in a hospital & $\begin{array}{l}\text { Hospice, palliative care unit (in a } \\
\text { hospital, nursing home, or care home) }\end{array}$ & Hospice & Palliative care unit in a hospital \\
\hline $\begin{array}{l}\text { Palliative care service for patients } \\
\text { staying at home }\end{array}$ & $\begin{array}{l}\text { Palliative home care team, } \\
\text { palliative day care centre }\end{array}$ & Palliative care consultation team ${ }^{*}$ & $\begin{array}{l}\text { Palliative home care team, domiciliary } \\
\text { integrated assistance with palliative care }\end{array}$ & $\begin{array}{l}\text { Palliative home care team, palliative } \\
\text { day care centre, ambulatory palliative } \\
\text { care in a hospital }\end{array}$ \\
\hline GP with palliative care training & $\S$ & GP with palliative care trainingt & $\S$ & $\S$ \\
\hline $\begin{array}{l}\text { In-house palliative care service in a } \\
\text { nursing home (excl. The Netherlands) }\end{array}$ & $\begin{array}{l}\text { Reference persons for palliative } \\
\text { care in a nursing home }\end{array}$ & $\|$ & $\|$ & Palliative care nurses in a nursing home \\
\hline $\begin{array}{l}\text { Hospital-based palliative care service } \\
\text { (excl. palliative care unit) }\end{array}$ & $\begin{array}{l}\text { Mobile palliative care support } \\
\text { team in a hospital }\end{array}$ & Palliative care consultation team ${ }^{*}$ & $\begin{array}{l}\text { Pain therapy or palliative care specialist } \\
\text { consultation during a hospital admission }\end{array}$ & $\|$ \\
\hline
\end{tabular}

"Palliative care consultation teams mainly offer services to patients at home but also to patients in hospital/hospice/nursing home.

${ }^{\dagger}$ GPs followed palliative care training offered by the Dutch Association of General Practitioners (Nederlands Huisartsen Genootschap, NHG); they are registered as palliative care advisors in a central database.

* For patients admitted to hospital for at least one day in the last three months of life.

${ }^{5}$ Not available/assessed in this country.

" Not available in this country. 
of previous retrospective and quantitative studies whenever possible $[6,15,20,37,41,42]$.

In case a specific concept could not be measured with an existing instrument, questions were developed on the basis of relevant literature and in dialogue with the all partners (the GP Networks and Researchers) and a Belgian/Dutch Advisory Board consisting of GPs, palliative care physicians, psychologists, nurses, medical sociologists, health scientists and an anthropologist. Also, new questions were tested among GPs before using them. Based on our previous experiences with GP registrations, we mainly used structured and closed-ended questions.

Questions were developed in Dutch and translated into French and English via forward-backward procedures. Italian and Spanish versions were developed from the English version via the same procedures. Translations were performed by independent native-speaking persons and discrepancies discussed and deliberated. The translation allowed for cultural differences in words or health care structures (eg differences in places of care, palliative care services). The registration form is shown in Additional file 1 in English.

\section{Feasibility testing}

An extensive pilot study to test the feasibility of the study design and the measurement instrument was performed in Belgium in 2004 [43]. For the EURO SENTIMELC study, the questionnaire was pretested in all countries using the following procedures:

a. 10-15 GPs (preferably sentinel GPs) per country were asked to fill in the registration form for pretesting purposes, in a face-to-face interview situation.

b. GPs were asked to fill in two registration forms: one for the most recent sudden and totally unexpected death case in their GP practice; and one for the most recent non-sudden or expected death case in their GP practice.

c. The physician filled in the registration form independently and without any help.

d. All physicians were asked to report any problem (out loud) that was encountered while filling in the registration form, concerning eg clarity of the questions, instructions for filling it in, difficulty of providing the requested information etc.). The time that was required to fill it in was also noted.

All issues were collected by the coordinator who made final decisions after consulting the partners.

\section{Ethical considerations}

The participating GPs were asked to give written informed consent at the beginning of a registration year, after being fully informed about the objectives and method of the research themes. If an existing GP network was used, the standard operating procedures within the Network were used. Additionally, strict procedures regarding patient anonymity are employed. Every patient that was registered within the network receives an anonymous reference from the GP him/herself. There also was supplementary coding of patient information i.e. the patient's date of birth might be registered by the GP but was replaced with the patient's age before dataentry, and postal code of habitual residence was transformed into more aggregate indicators such as province and region of care. Concerning the GPs' identity, all his/her identification codes were replaced in the data files with anonymous codes during data cleaning in each country.

The protocol of the present study was approved by the Ethical Review Board of Brussels University Hospital of the Vrije Universiteit Brussel and the Local Ethical Committee 'Comitato Etico della Azienda U.S.L. n. 9 di Grosseto', Tuscany. According to specific regulations, no specific ethical approvals were needed in the Netherlands or Spain because of the retrospective and anonymous data collection.

\section{Data management and statistical analysis}

Each GP network had its own control measures to ensure data quality and to limit missing data (see Table 3 for details). A common format for coding of variables, used by all partners, was made by the coordinator, who also merged all files. All operations were stored via SPPS syntax-files.

To verify if a representative population-based sample of deaths can be obtained via this representative sample of GPs, we evaluated whether the deaths registered by the Sentinel Network of GPs are comparable in terms of age, sex and place of death to the deaths occurring within the general population or to the characteristics of the nonsudden deaths within the population (if possible).

\section{Results}

The number of participating GPs and their population coverage per country in 2009 was 199 (1.8\%) in Belgium, $59(0.8 \%)$ in the Netherlands, and 149 (4.3\%) in Italy. The respective figures for 2010 were 189 (1.5\%) in Belgium, $63(0.8 \%)$ in the Netherlands, 94 (2.7\%) in Italy, and 173 in Spain (114 (3.4\%) in Castilla and León, 59 (3\%) in Valencia).

Table 5 shows the number and characteristics of the registered deaths in the EURO SENTIMELC study of 2009-2010 and of the percentages of nonsudden deaths in each country. A total of 6858 deaths were registered of which two thirds died non-suddenly (from 62\% in the Netherlands to $69 \%$ in Spain). Of these non-sudden 
Table 5 Number and characteristics of reported deaths in the EURO SENTIMELC study 2009-2010

\begin{tabular}{|c|c|c|c|c|c|c|c|c|c|}
\hline & & Belgium & & The Nether & lands* & Italy & & Spain $†$ & \\
\hline & & All deaths & $\begin{array}{c}\text { Non-sudden } \\
\text { deaths§ }\end{array}$ & All deaths & $\begin{array}{c}\text { Non-sudden } \\
\text { deaths§ }\end{array}$ & All deaths & $\begin{array}{c}\text { Non-sudden } \\
\text { deaths§ }\end{array}$ & All deaths & $\begin{array}{c}\text { Non-sudden } \\
\text { deaths } \S\end{array}$ \\
\hline & & $N=2405$ & $\begin{array}{c}N=1604 \\
(66.7 \%)\end{array}$ & $N=1107$ & $\begin{array}{l}N=635 \\
(62.1 \%)\end{array}$ & $N=2783$ & $\begin{array}{c}N=1839 \\
(66.1 \%)\end{array}$ & $N=563$ & $\begin{array}{l}N=388 \\
(68.9 \%)\end{array}$ \\
\hline & & $\%$ & $\%$ & $\%$ & $\% \dagger$ & $\%$ & $\%$ & $\%$ & $\%$ \\
\hline Age & $18-64$ & 16 & 14 & 21 & 18 & 13 & 13 & 11 & 11 \\
\hline & $65-84$ & 47 & 47 & 50 & 50 & 48 & 47 & 46 & 45 \\
\hline & $85+$ & 37 & 39 & 29 & 32 & 39 & 40 & 43 & 44 \\
\hline Gender & Male & 48 & 46 & 52 & 47 & 48 & 47 & 53 & 54 \\
\hline & Female & 52 & 54 & 48 & 53 & 52 & 53 & 47 & 46 \\
\hline Place of death $\neq$ & Home & 29 & 23 & 45 & 44 & 48 & 46 & 48 & 49 \\
\hline & $\begin{array}{l}\text { Care or residential } \\
\text { home }\end{array}$ & 27 & 31 & 14 & 18 & 7 & 9 & 11 & 13 \\
\hline & Hospital & 37 & 36 & 32 & 28 & 39 & 39 & 37 & 33 \\
\hline & PCU/hospice & 7 & 9 & 7 & 10 & 4 & 5 & 4 & 4 \\
\hline Cause of death & Cancer & 28 & 37 & 37 & 53 & 34 & 46 & 35 & 39 \\
\hline & Noncancer & 72 & 63 & 63 & 47 & 66 & 54 & 65 & 61 \\
\hline
\end{tabular}

*Excluding nursing home deaths in the Netherlands.

† Data for Spain are available only for the year 2010.

fIT and SP: each $1 \%$ POD elsewhere.

$\S \%$ missing on nonsudden deaths : $0.7 \%$ for $\mathrm{Be}, 0 \%$ for the $\mathrm{Ne}, 1.7 \%$ for It and $5.9 \%$ for SP.

Percentages are rounded off hence cells may not add up to $100 \%$.

deaths between $32 \%$ and $44 \%$ of deaths were aged 85 or older; between $46 \%$ and $54 \%$ were female, and between $23 \%$ and $49 \%$ died at home. Cancer was cause of death in $37 \%$ to $53 \%$ of non-sudden death cases.

Table 6 also compares the characteristics of the registered sample with the characteristics of a reference population. In Belgium and the Netherlands, figures for all non-sudden deaths are compared with a previous death certificate study on end-of-life decisions (in 2007 for Belgium and 2005 for the Netherlands) in which a representative sample of nonsudden deaths was obtained after weighting [37,44]. For Italy and Spain, figures for all deaths are compared with the total death rates in the country or in the reference population. Overall we find no large differences between the obtained SENTIMELC samples and the reference populations. In all countries, GPs can identify deaths due to cancer and noncancer, dying at home as well as in institutional settings. We do see a slight underrepresentation of nonsudden hospital deaths and people under the age of 65 in Belgium and a slight underrepresentation of females in the Netherlands. We assume that GPs in Spain and Italy might also miss out on some of the sudden deaths occurring in the hospitals, but cannot test this hypothesis due to the absence of place of death information on death certificates.

\section{Discussion}

The objectives of the EURO SENTIMELC study are to describe end-of-life care provided to patients who had died non-suddenly in Belgium, the Netherlands, Italy and Spain and to make cross-country comparisons. We also aim to investigate patient, disease and healthcare characteristics associated with variations in end-of-life care. To realize these objectives, this retrospective study with data collection via four representative Networks of General Practitioners was set up.

\section{Interpretation of the main findings}

The need for setting up standardized continuous systems to monitor where and how people die has been recognized worldwide [1,3-5]. The lack of population-based and nationwide studies on end- of-life care hampers the ability to develop an effective public health policy on end-of-life care and has been identified as a major gap in end-of-life research today. Also, improving clinical practice starts with good monitoring of the current situation [1,3-5].

Death certificate data or mortality statistics are by far the most known public health method used to inform where, at what age and due to what cause deaths occur in a country $[6,46]$. However, the resulting data are very limited in scope eg they do not included data on the circumstances of dying and place of death is coded in a limited way (eg in most countries palliative care units cannot be differentiated from hospital deaths and in some other countries hospital deaths can only be distinguished from deaths in 'other places') [46]. Several 
Table 6 Representativitity of reported deaths in the EURO SENTIMELC study 2009-2010

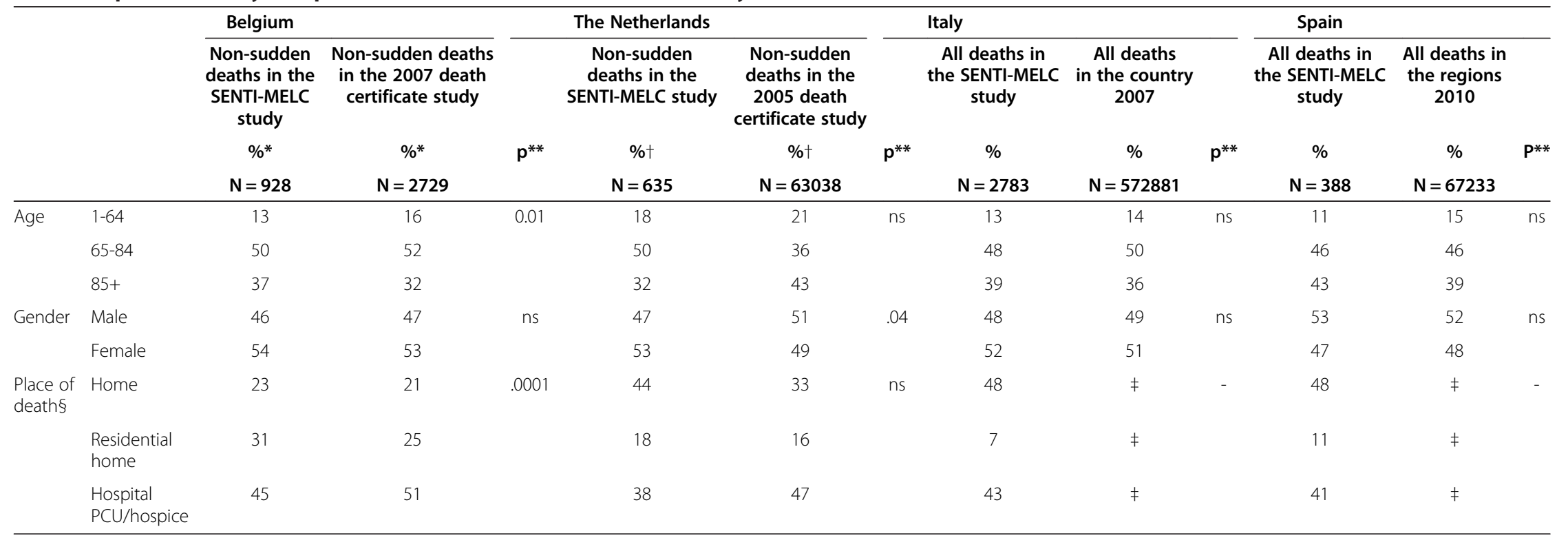

* Numbers for Flanders, the Dutch-speaking part of the country (60\% of the population) only, due to absence of death certificates database in the French-speaking part of Belgium.

† Excluding nursing home deaths in the Netherlands.

\# Unknown for Italy and Spain. Although data on place of death are not available in Italy from the national official statistics, the results for cancer deaths were similar to the ISDOC study figures of 2003 [45].

§ IT and SP: each 1\% POD elsewhere; BE 3\% other.

**p-values using Fisher exact test. 
efforts have been made to explore data relevant for endof-life care in existing large-scale databases such as disease registries, hospital discharge registers, diseasespecific registers or healthcare billing data $[7,16,17,47]$. However, no data source is totally comprehensive and all have their specific limitations on a national and international comparative level. Tracking patients, cancer and non-cancer, throughout the health care systems transferring between health care settings- has been found to be particularly challenging in end-of-life care research today $[1,4,16]$. Hence, using primary care GP networks that register data which is not systematically gathered via other data collection systems is of considerable added value for monitoring death and dying from a societal point of view, comparing countries and providing a good basis for continuous surveillance. Our results show that representative samples of GPs in the four countries involved have the potential of providing a good public health perspective on end-of-life care and dying in a country.

This study has several potential strengths as well as limitations associated with the use of an (existing) surveillance network of GPs in general, and with the specific design of the study.

\section{Strengths}

The Sentinel Network of General Practitioners in Belgium, the Netherlands and Spain are representative of all GPs in the country or region, have a long tradition in scientific research, are flexible in terms of acceptability of new registrations, and very stable in terms of participating GPs. The GPs are motivated to monitor various health-related problems over long and repeated periods, but have not been selected on the basis of a specific interest in end-of-life research. In Italy, where a new network has been set up, GPs were not informed about the content of the research beforehand to avoid selection of GPs more trained than the average GP in palliative care. They were selected to be representative for 9 large health districts distributed all over the country. However, the GPs that are motivated to participate in these type of registration networks, might still represent a selective group of physicians interested in scientific research, a limitation that is probably also present in other studies.

Because detailed information concerning the care provided is not always available from the patients' medical files, nor from existing deaths registers such as death certificate data, a registration directly with GPs has important surplus value. Using the representative networks, we could obtain samples of deaths representative for the GP populations in the participating countries. A specific strength of this retrospective study is that memory bias found in other retrospective designs [22,36], will be limited, because of the weekly registrations, leaving little time between death and registration. Also, identification of non-sudden deaths as denominator is an advantage over other prospective and retrospective designs that have been criticized for selecting patients solely on the basis of diagnose or cause of death. Not all patients with a cancer diagnose, for example, also die of cancer or receive care with an end-of-life intent [23,48]. By avoiding including patients that died suddenly and unexpectedly, we will be able to study care that was truly delivered in the context of a dying process. Additionally, while retrospective designs may have their limitations to resurrect certain aspects of the treatment histories of deceased patients [48], it is the most appropriate design to identify a representative sample of deaths and to make population-based estimates about who received palliative care $[49,50]$. Prospective follow-up studies cannot follow all patients until death hence leaving patients living the longest underrepresented [23,51]. Another strength concerns the possibility of making cross-country comparisons in populations attended by GPs and in the care provided at the end of life, using analogous methodologies. Finally, many different end-of-life topics can be studied via GPs.

\section{Weaknesses}

The registration form is to be kept simple, and timeconsuming questions should be avoided in a surveillance system. Consequently, in-depth study of some aspects of care is generally not possible via this type of registration research and observed cross-country differences might be difficult to explain [18]. Possible weaknesses also include the retrospective data collection approach making reconstruction of all care provided in the final three months of life difficult [22] and the reliance on GPs to report care and decisions at the end of life, including care delivered to patients in hospitals or decisions taken by hospital physicians. An underestimation of specific types of care provided or decisions taken is thus possible. A specific weakness for Belgium is that there are no patient lists per practice, hence the population denominator (the "sentinel population") is not precisely defined and has to be estimated on the basis of annual total number of patient encounters in the participating practices [52]. Additionally, while using the same methodology in the different countries, the population of dying patients that is taken care of by the GP differs per country - e.g. we lack nursing home deaths in the Netherlands - which makes it necessary to correct for these differences when comparing countries. Finally, GPs appear to underreport a limited number of deaths ie non-sudden hospital deaths and deaths of people under 65 years old in Belgium, and possibly also sudden hospital deaths in all countries. 


\section{Opportunities for further research}

Because data can be gathered over time, we will, in the long-run, evaluate the monitoring potential of this instrument. The results could potentially serve as baseline data to monitor end-of-life care over time. Also, since many other European countries have at least one Sentinel Network of GPs $[18,29]$, the study provides opportunities for further comparisons with other countries. The nationwide Sentinel Network from France has expressed interest and other countries are being contacted to join this monitoring study in 2013. Finally, the EURO SENTIMELC database is made available for the EURO IMPACT project, a EU funded Marie Curie Initial Training Network aimed at describing quality of end-of-life care for cancer and noncancer patients and identifying tools to improve it (www.euro-impact.eu) that is researchers will analyse and publish the obtained data. This creates important opportunities for large scale dissemination of the results nationally and internationally.

\section{Conclusions}

In the EURO SENTI-MELC study, we will build a public health database on how people are dying and what care they are receiving at the end of life in different countries in Europe and make cross-country comparisons. It will provide important information for practitioners and healthcare policy makers which they can use to determine their future priorities.

\section{Additional file}

\section{Additional file 1: Registration form of EURO SENTIMELC study} 2009-2010 file name deces 2010 ENG file format.

\section{Abbreviations \\ SENTI-MELC: Sentinel network Monitoring End-of-Life Care; GP: General practitioner.}

\section{Competing interests}

The authors declare that they have no competing interests.

\section{Authors' contributions}

LVDB, BOP, GD, GM, WC, TVA and LD were involved in the conception and design of the study. LVDB, KM, GD, FG, WV, TVA, and OZ gathered the data. Statistical analyses are carried out by LVDB. The manuscript was drafted by LVDB with critical input from all other authors. LVDB was the project supervisor. All authors read, revised and approved the final manuscript.

\section{Acknowledgements}

The first author has a postdoctoral mandate grant from the Fund for Scientific Research in Flanders, Belgium. Support for the study came from the Institute for the Promotion of Innovation by Science and Technology in Flanders as a Strategic Basic Research project (SBO) (contract SBO IWT 050158) (2006-2010), as part of the 'Monitoring Quality of End-of-Life Care (MELC) Study', a collaboration between the Vrije Universiteit Brussel, Ghent University, Antwerp University, the Scientific Institute for Public Health, Belgium, and VU University Medical Centre Amsterdam, the Netherlands. The authors would like to thank all participating sentinel GPs providing data for this study and all members of the Sentinel Networks.

\section{Author details}

${ }^{1}$ End-of-Life Care Research Group, Vrije Universiteit Brussel and Ghent University, Laarbeeklaan 103, Brussels 1090, Belgium. ²Department of Public and Occupational Health, EMGO Institute for Health and Care Research, VU University Medical Center, Van der Boechorststraat 7, Amsterdam, BT 1081, The Netherlands. ${ }^{3}$ Dutch Sentinel General Practice Network, NIVEL, Otterstraat 118-124, Utrecht, CR 3513, The Netherlands. ${ }^{4}$ Cancer Prevention and Research Institute, ISPO, Via Oblate 2,Pal 28/A, Florence 50142, Italy.

${ }^{5}$ Scientific Institute of Public Health, J. Wytsmanstraat 14, Brussels 1050, Belgium. ${ }^{6}$ Public Health Directorate, Junta de Castilla y León, Paseo Zorilla 1, Valladolid 47071, Spain. ${ }^{7}$ Dirección General de Salud Pública, Conselleria de Sanidad, Valencia, Spain. ${ }^{8}$ Spanish Consortium for Research in Epidemiology and Public Health CIBERESP, Madrid, Spain.

Received: 12 January 2013 Accepted: 28 May 2013 Published: 3 June 2013

\section{References}

1. Palliative care The solid facts. Edited by Davies E, Higginson I. Milan: WHO; 2004:1-32.

2. Hall S, Petkova H, Tsouros AD, Costantini M, Higginson I: Palliative care for older people: better practices. Denmark: World Health Organization; 2011.

3. Morrison RS, Siu AL, Leipzig RM, Cassel CK, Meier DE: The hard task of improving the quality of care at the end of life. Arch/nternMed 2000, 160(6):743-747.

4. Grady PA: Introduction: papers from the National Institutes of Health State-of-the-Science Conference on Improving End-of-Life Care. J Palliat Med 2005, 8(Suppl 1):S1-3.

5. Cohen J, Deliens L: A Public Health Perspective on End of Life Care. New York: Oxford University Press; 2012.

6. Cohen J, Bilsen J, Addington-Hall J, Löfmark R, Miccinesi G, Kaasa S, Onwuteaka-Philipsen B, Deliens L: Population-based study of dying in hospital in six European countries. Palliat Med 2008, 22(6):702-710.

7. Earle CC, Park ER, Lai B, Weeks JC, Ayanian JZ, Block S: Identifying potential indicators of the quality of end-of-life cancer care from administrative data. JClinOncol 2003, 21(6):1133-1138.

8. A controlled trial to improve care for seriously ill hospitalized patients. The study to understand prognoses and preferences for outcomes and risks of treatments (SUPPORT). The SUPPORT Principal Investigators. JAMA 1995, 274(20):1591-1598.

9. Somogyi-Zalud E, Zhong Z, Lynn J, Hamel MB: Elderly persons' last six months of life: findings from the Hospitalized Elderly Longitudinal Project. JAmGeriatrSoc 2000, 48(5 Suppl):S131-S139.

10. Brandt HE, Deliens L, Ooms ME, van der Steen JT, Van der WG, Ribbe MW: Symptoms, signs, problems, and diseases of terminally ill nursing home patients: a nationwide observational study in the Netherlands. ArchlnternMed 2005, 165(3):314-320.

11. Earle CC, Neville BA, Landrum MB, Ayanian JZ, Block SD, Weeks JC: Trends in the aggressiveness of cancer care near the end of life. JClinOncol 2004, 22(2):315-321.

12. Ganzini $L$, Johnston WS, Silveira MJ: The final month of life in patients with ALS. Neurology 2002, 59(3):428-431.

13. Higginson IJ, Astin P, Dolan S: Where do cancer patients die? Ten-year trends in the place of death of cancer patients in England. PalliatMed 1998, 12(5):353-363.

14. Addington-Hall JM, O'Callaghan AC: A comparison of the quality of care provided to cancer patients in the UK in the last three months of life in in-patient hospices compared with hospitals, from the perspective of bereaved relatives: results from a survey using the VOICES questionnaire. Palliat Med 2009, 23(3):190-197.

15. Teno JM, Clarridge BR, Casey V, Welch LC, Wetle T, Shield R, Mor V: Family perspectives on end-of-life care at the last place of care. JAMA 2004, 291(1):88-93.

16. (IOM) loM: Describing Death in America: What We Need to Know. Washington DC, US: National Academy Press; 2003.

17. Allan DE, Stajduhar Kl, Reid RC: The uses of provincial administrative health databases for research on palliative care: Insights from British Columbia. Canada. BMCPalliatCare 2005, 4(1):2.

18. Fleming DM, Schellevis FG, Paget WJ: Health monitoring in sentinel practice networks: the contribution of primary care. EurJPublic Health 2003, 13(3 Suppl):80-84. 
19. Van den Block L, Deschepper R, Bossuyt N, Drieskens K, Bauwens S, Van Casteren V, Deliens L: Care for patients in the last months of life - The Belgian Sentinel Network Monitoring End-of-Life Care study. Archives of Internal Medicine 2008, 168(16):1747-1754.

20. Van den Block L, Van Casteren V, Deschepper R, Bossuyt N, Drieskens K, Bauwens S, Bilsen J, Deliens L: Nationwide monitoring of end-of-life care via the Sentinel Network of General Practitioners in Belgium: the research protocol of the SENTI-MELC study. BMC Palliat Care 2007, 6:6.

21. Meeussen K, Van den Block L, Echteld MA, Boffin N, Bilsen J, Van Casteren V, Abarshi E, Donker G, Onwuteaka-Philipsen B, Deliens L: End-of-life care and circumstances of death in patients dying as a result of cancer in Belgium and the Netherlands: a retrospective comparative study. J Clin Oncol 2011, 29(32):4327-4334.

22. Teno JM: Measuring end-of-life care outcomes retrospectively. JPalliatMed 2005, 8(Suppl 1):S42-S49.

23. Earle CC, Ayanian JZ: Looking back from death: the value of retrospective studies of end-of-life care. J Clin Oncol 2006, 24(6):838-840.

24. Abarshi E, Echteld MA, den BL V, Donker G, Bossuyt N, Meeussen K, Bilsen J, Onwuteaka-Philipsen B, Deliens L: Use of Palliative Care Services and General Practitioner Visits at the End of Life in The Netherlands and Belgium. JPain Symptom Manage 2010.

25. Bossuyt N, Van den Block L, Cohen J, Meeussen K, Bilsen J, Echteld M, Deliens L, Van Casteren V: Is individual educational level related to end-of -life care use? Results from a nationwide retrospective cohort study in Belgium. J Palliat Med 2011, 14(10):1135-1141.

26. Abarshi E, Echteld MA, Van den Block L, Donker G, Bossuyt N, Meeussen K, Bilsen J, Onwuteaka-Philipsen B, Deliens L: Use of palliative care services and general practitioner visits at the end of life in The Netherlands and Belgium. J Pain Symptom Manage 2011, 41(2):436-448.

27. Meeussen K, Van den BL, Bossuyt N, Bilsen J, Echteld M, Van CV, Deliens L: GPs' awareness of patients' preference for place of death. BrJGenPract 2009, 59(566):665-670.

28. Van den Block L, Deschepper R, Bilsen J, Van Casteren V, Deliens L: Transitions between care settings at the end of life in Belgium. JamaJournal of the American Medical Association 2007, 298:1638-1639.

29. Deckers J, Schellevis F: Health information from primare care: final report December 12011 - March 31 2004. In Nivel. the Netherlands.

30. Vega Alonso A, Zurriaga Llorens O, Galmes Truyols A, Lozano Alonso J, Paisan Maestro L, Gil Costa M, Herrero Llorente A: Ramos Aceitero J, project obotrgotR: Guide to the principles and methods of health sentinel networks in Spain. Gac Sanit 2006, 20(6):496-502.

31. Boffin N, Vanthomme K, Van Casteren V: The Belgian network of Sentinel General Practices in 2011. WIV/ISP: Brussels; 2012. https://www.wiv-isp.be/ epidemio/epinl/index10.htm.

32. Donker G: Continuous Morbidity Registration Dutch Sentinel General Practice Networks 2011. In. Utrecht, the. Netherlands: Nivel; 2011.

33. Sanidad C: Procedimientos y documentación de la Red Centinela Sanitaria de Castillay y Léon_v3. http://www.saludcastillayleon.es/profesionales/es/ centinelas/red-centinela-sanitaria-castilla-leon.

34. Sanidad C: Informe nr 68 de la Red Centinal Sanitaria de Castilly y Léon. ; 2006. http://www.saludcastillayleon.es/profesionales/es/centinelas/informesred-centinela-sanitaria-castilla-leon.

35. Pública DGdS: Generalitat Valenciana. Red Centinela sanitaria. http://www.sp. san.gva.es/red_centinela.

36. van der Heide A, Deliens L, Faisst K, Nilstun T, Norup M: Paci E, van der WG, van der Maas PJ: End-of-life decision-making in six European countries: descriptive study. Lancet 2003, 362(9381):345-350.

37. Bilsen J, Cohen J, Chambaere K, Pousset G, Onwuteaka-Philipsen BD, Mortier F, Deliens L: Medical end-of-life practices under the euthanasia law in Belgium. NEnglJMed 2009, 361(11):1119-1121.

38. Teno JM, Casey VA, Welch LC, Edgman-Levitan S: Patient-focused, familycentered end-of-life medical care: views of the guidelines and bereaved family members. JPain Symptom Manage 2001, 22(3):738-751.

39. Casarett DJ, Teno J, Higginson I: How should nations measure the quality of end-of-life care for older adults? Recommendations for an international minimum data set. J Am Geriatr Soc 2006, 54(11):1765-1771.

40. CtICotDalfH I: Improving Care for the End of Life: A Sourcebook for Health Care Managers and Clinicians. Oxford: Oxford University Press; 2000.

41. Addington-Hall J, McCarthy M: Regional Study of Care for the Dying: methods and sample characteristics. PalliatMed 1995, 9(1):27-35.
42. Addington-Hall J, McPherson C: After-death interviews with surrogates/ bereaved family members: some issues of validity. JPain Symptom Manage 2001, 22(3):784-790

43. Van den Block L, Deschepper R, Drieskens K, Bauwens S, Bilsen J, Bossuyt N, Deliens $L$ : Hospitalisations at the end of life: using a sentinel surveillance network to study hospital use and associated patient, disease and healthcare factors. Bmc Health Services Research 2007, 7.

44. Onwuteaka-Philipsen BD, Brinkman-Stoppelenburg A, Penning C, De JongKrul GJ, Van Delden JJ, van der Heide A: Trends in end-of-life practices before and after the enactment of the euthanasia law in the Netherlands from 1990 to 2010: a repeated cross-sectional survey. Lancet 2012, 380(9845):908-915

45. Beccaro M, Costantini M, Giorgi Rossi P, Miccinesi G, Grimaldi M, Bruzzi P, Group IS: Actual and preferred place of death of cancer patients. Results from the Italian survey of the dying of cancer (ISDOC). J Epidemiol Community Health 2006, 60(5):412-416.

46. Cohen J, Bilsen J, Miccinesi G, Löfmark R, Addington-Hall J, Kaasa S, Norup $M$, van der Wal G, Deliens L: Using death certificate data to study place of death in 9 European countries: opportunities and weaknesses. BMC Public Health 2007, 7:283.

47. Deckers JG, Paget WJ, Schellevis FG, Fleming DM: European primary care surveillance networks: their structure and operation. Fam Pract 2006, 23(2):151-158.

48. Bach PB, Schrag D, Begg CB: Resurrecting treatment histories of dead patients: a study design that should be laid to rest. JAMA 2004, 292(22): 2765-2770.

49. Teno JM, Mor V: Resurrecting treatment histories of dead patients. JAMA 2005, 13:1591. uthor reply 1592

50. Barnato $A E$, Lynn J: Resurrecting treatment histories of dead patients. JAMA 2005, 293(13):1591-1592. author reply 1592.

51. van der Steen JT, Deliens L, Ribbe MW, Onwuteaka-Philipsen BD: Selection bias in family reports on end of life with dementia in nursing homes. J Palliat Med 2012, 15(12):1292-1296.

52. Lobet MP, Stroobant A, Mertens R, Van Casteren V, Walckiers D, MasuyStroobant G, Cornelis R: Tool for validation of the network of sentinel general practitioners in the Belgian health care system. Int J Epidemiol 1987, 16(4):612-618

doi:10.1186/1471-2296-14-73

Cite this article as: Van den Block et al:: Nationwide continuous monitoring of end-of-life care via representative networks of general practitioners in Europe. BMC Family Practice 2013 14:73.

\section{Submit your next manuscript to BioMed Central and take full advantage of:}

- Convenient online submission

- Thorough peer review

- No space constraints or color figure charges

- Immediate publication on acceptance

- Inclusion in PubMed, CAS, Scopus and Google Scholar

- Research which is freely available for redistribution 